RASĀYAN J. Chem.

Vol. 12 | No. 4 |2284 - 2289| October - December | 2019 ISSN: 0974-1496 | e-ISSN: 0976-0083 | CODEN: RJCABP

RJC http://www.rasayanjournal.com http://www.rasayanjournal.co.in

\title{
GC-MS ANALYSIS OF VOLATILE ACTIVE COMPOUNDS ISOLATED FROM Aspergillus sp OF Rhizophora mucronata
}

\author{
O. Fadriyanti ${ }^{1, *}$, I. D. Nasution ${ }^{2}$, D. Handayani ${ }^{3}$ and W. Siswomiharjo ${ }^{4}$ \\ ${ }^{1}$ Doctoral Program, Faculty of Dentistry, Universitas Sumatera Utara, Medan, Indonesia \\ ${ }^{2}$ Department of Prosthodontics, Faculty of Dentistry, Universitas Sumatera Utara, \\ Medan, Indonesia \\ ${ }^{3}$ Sumatera Biota Laboratory, Faculty of Pharmacy, Universitas Andalas, Padang, Indonesia \\ ${ }^{4}$ Department of Dental Material, Faculty of Dentistry, Universitas Gadjah Mada, \\ Yogyakarta Indonesia \\ *E-mail: okmes.unbra@gmail.com
}

\begin{abstract}
This study aimed to identify anti-bacterial compounds consisted of the ethyl acetate fraction of Aspergillus sp extracted from the root of Rhizophora mucronata. The sample of Aspergillus sp cultivated from mangrove located in West Sumatera province. Each culture isolated was macerated in the ethyl acetate and analyzed using GC-MS instrumentation. The GC-MS spectra indicated fifteen compounds including isoindole derivative, organic acids (3 compounds), organic acid ester (4 compounds), acetate derivative, acetone derivative, alcohol derivatives (3 compounds) and naphthalene derivative. Among the identified compounds, 4-isopropyl-1,6-dimethyl-1,2,3,4,4A,7hexahydronaphtalene, trifluoroacetyl-isopulegol, 2-ethyl-2,4,5-trimethyl-1,3-dioxolane and 4-isopropyl-1,6dimethyl-1,2,3,4,4A,7-hexahydronaphthalene were reported as antibacterial and antimicrobial compounds.
\end{abstract}

Keywords: GC-MS, Biological Activities, Aspergillus sp, Rhizophora mucronata.

(C) RASĀYAN. All rights reserved

\section{INTRODUCTION}

Endophyte mould primarily resides in the tissues below the epidermal cell layers of the plants without harming the host ${ }^{1}$. Recent studies have shown that from over three hundred thousand species of plants that survive on the earth, nearly every single species is the host to at least one kind of endophytic fungi. The fungi can usually found in leaves, but it can also be manifested in the gasp of the root as the main entry door for all kinds of a microorganism to penetrate the plant. The colony can positively affect the mass plants by protecting the inner part of a plant from other microbial or bacterial attacks since the endophytic fungi exhibit sort of chemicals that actively defend the inner part of a plant from the incoming intruders like the pathogens. Furthermore, two stated that the endophytic fungi provides some benefits to the host plants including insect deterrence, mammalian herbivores deterrence, reduction of nematodes, increase the resistance of host disease, avoiding abiotic stress, increase the host biomass and protection from pathogens.

Aspergillus sp is the endophytic mould belongs to the group of Filamentous Deuteromycetes ${ }^{2}$ which is highly aerobic growing on carbon-rich substrates contained either monosaccharide or polysaccharide ${ }^{3}$. Aspergillus $s p$ is a fungus that forms long branched filaments, and in culture media, it forms mycelia and conidiophores. This species reproduces by forming hyphae or buds and produces spore-forming conidiophores.

Endophytic fungi have great potential as new sources of medicine since the microbes are easy to breed, have a short life cycle and can produce large amounts of bioactive compounds in a short time. Endophytic fungi are known as a source of abundant secondary metabolites and are very interesting ${ }^{4}$ in terms of activity and chemical structure. In addition to heavy secondary metabolite molecules like alkaloids,

Rasayan J. Chem., 12(4), 2284-2289(2019)

http://dx.doi.org/10.31788/RJC.2019.1245415

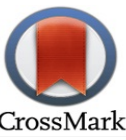


flavonoids and peptides, the endophytic fungi also produce volatile compounds such as organic acids, organic ester and alcohols which can be determined using GC-MS instrumentation.

Since the secondary plant metabolites generated by a fungus can mutually benefit the host plant, the chemicals produced are expected to have a similar effect on protecting human body parts like tooth or nails. Therefore, this paper presents the volatile compounds generated by the endophytic fungi cultivated from the mangrove roots, and analyze the potential of the substances as anti-fungi, anti-bacterial and antimicrobial agents.

\section{Materials and Methods}

\section{EXPERIMENTAL}

The endophytic fungus cultivated from the district of Pantai Pasir Jambak, West Sumatera Province, Indonesia. The materials used in this research were ethyl acetate (Merck), ethanol (Sigma-Aldrich), filter paper and demineralized water. The cold macerated extraction was performed to collect the ethyl acetate fraction of the fungus. The volatile constituents were analyzed using GC-MS instrument.

\section{Extraction of endophytic fungus}

The extraction technique referred to the method modified by NY N (2018) ${ }^{5}$. Each cultured isolate and immersed in $300 \mathrm{~mL}$ of acetic acid for 96 hours. After four days, the concentrate was filtered using Whatman filter paper No. 1 until the ethyl acetate fraction obtained. The fraction was then evaporated using Rotary Evaporator (Perkin Elmer 6000), and the concentrated isolate stored for GCMS determination.

\section{GC-MS Analysis}

The GC-MS analysis of the ethyl acetate extract of Aspergillus conducted at the Provincial Health Laboratory of Special Capital of Jakarta using a Shimadzu QP2010PLUS system comprising an AOC-20i auto-sampler and the GC coupled to a Mass Spectrometer equipped with an Elite-5MS fused a capillary column of $30 \times 0.25 \mu \mathrm{m}$ ID $\times 0.25 \mu \mathrm{m}$ df. The electron ionization system operated in electron impact mode with ionization energy of $60 \mathrm{eV}$. The carrier gas set up at a constant flow rate of $1 \mathrm{~mL} / \mathrm{min}$ with an injection volume of $2 \mu \mathrm{l}$.

\section{RESULTS AND DISCUSSION}

The GC spectrum of ethyl acetate extract of endophytic fungus (Fig.-1) confirmed the presence of at least 21 components with different retention times as concisely depicted by Table-1. The mass spectrometer analyses the compounds eluted at various times to identify the nature of the compounds by showing compound fragments at different $\mathrm{m} / \mathrm{z}$ ratios. From 21 components found in the ethyl acetate extract, there are six significant compounds with the peak area of more than $4 \%$ as explained later in this article.

\section{Major Components}

3-Hydroxybutan-2-one

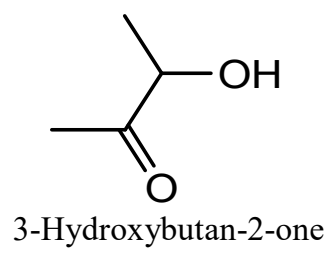

3-hydroxybutan-2-one or acetoin is a fermented product that generated by the butanediol life cycle of organism wherein mammals this compound turns to $\mathrm{CO}_{2}$. The dimerization of acetoin resulted in the crystalline structure. In industries, this compound is used as a food additive and was among important chemicals prioritized by US Department of Technology for development and utilization ${ }^{6}$. Acetoin can be produced either through chemical synthesis or biological synthesis, but enzymatic synthesis is favorable due to cost efficiency ${ }^{7}$. Therefore, several research findings reported acetoin production using various yeasts, including Saccharomyces cerevisiae ${ }^{8}$ Lactococcus $_{\text {lactis }}{ }^{9}$, Bacillus myloliquefaciens ${ }^{10}$, and Serratia marcescens ${ }^{11}$. Generally, almost all fermentation process generates acetoin with different ratios. 
RASĀYAN J. Chem.

Vol. 12 | No. 4 |2284 - 2289| October - December | 2019

\section{4-Isopropyl-1,6-dimethyl-1,2,3,4,4A,7-hexahydronaphtalene}<smiles>CC1=CC2C(=CC1)C(C)CCC2C(C)C</smiles>

4-isopropyl-1,6-dimethyl-1,2,3,4,4A,7-hexahydronaphtalene

This compound is a derivative form of the naphthalene group with ten carbon member rings. Some reports revealed that this compound mainly found in Syzygium aromaticum oil ${ }^{12}$, black pines ${ }^{13}$, and cardamom oil. With a combination of other active components of the oil, this compound has been reported to have antioxidant activity, anti-inflammatory and antimutagenic ${ }^{14}$. The compound is relatively similar in terms of chemical structure to the eugenol family, a group of a compound that has a significant effect against bacteria ${ }^{15}$.

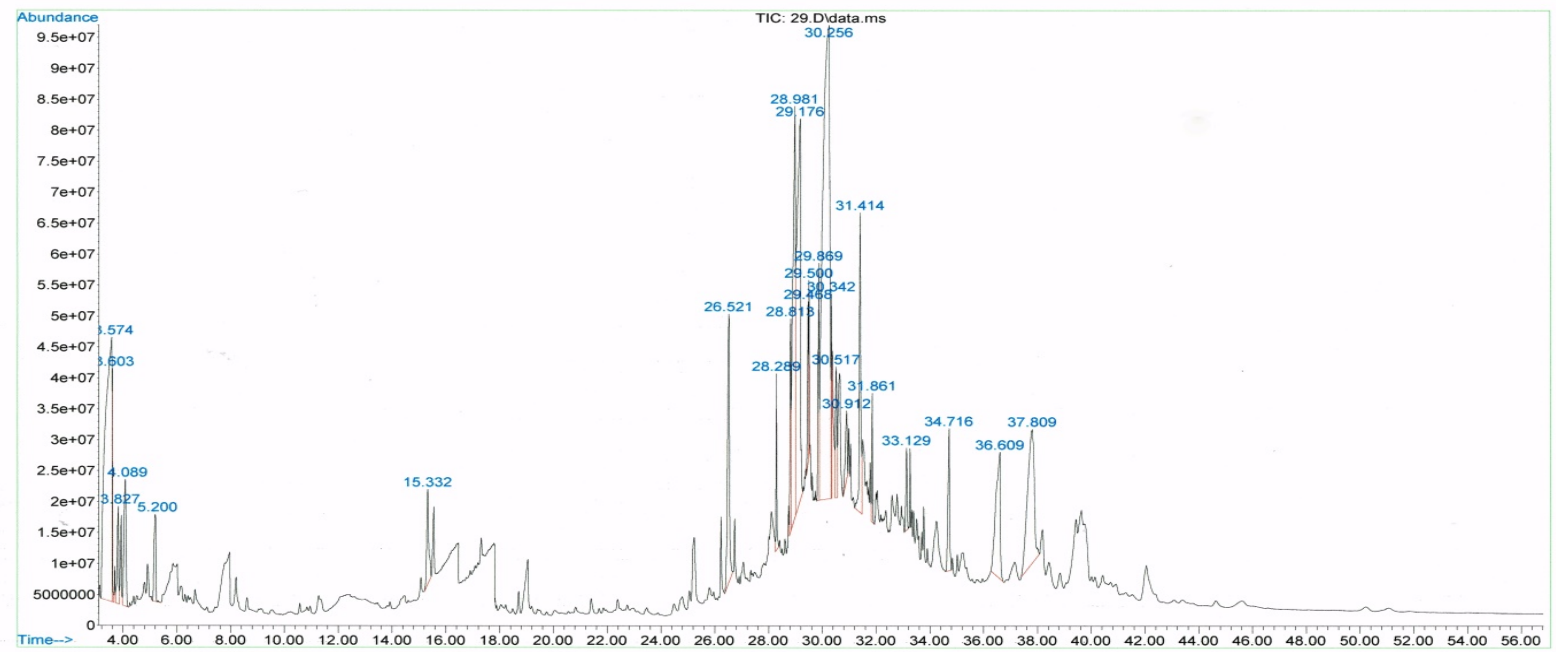

Fig.-1: Typical GC Spectrum of Endophytic Fungus Extract

\section{7-Pentadecyne,-9-methylene}<smiles>C=C(C#CCCCCCC)CCCCCC</smiles>

7-Pentadecyne,-9-methylene

7-pentadecyne,-9-methylene is the member of alkyne that Giacomelli in 1979 synthesized it by introducing the synthesis of dialkyl-butyne through the reaction of acetylene diisobutyl zinc with a nickel catalyst. Naturally, the fungus metabolism process generates alkyne group compounds. Most of the alkyne group compound has been reported to have antimicrobial and antifungal activities ${ }^{16}$. Furthermore, the structural analysis of the compound shown that the compound has a positive Milog $p$ indicated the bioactivity of the compound ${ }^{17}$.

\section{Hexadecanoic acid}<smiles>CCCCCCCCCCCCCCCC(=O)O</smiles>

Hexadecanoic Acid 
RASĀYAN J. Chem.

Vol. 12 | No. 4 |2284 - 2289| October - December | 2019

Hexadecanoic acid is trivially known as palmitic acid and is ubiquitous organic acid found in various sources like coconut oil, palm oil, and nuts. In nature, this compound is available as triglyceride and used as a food additive and preservative agent. Besides, this organic acid also gives a mitotic effect to test mice ${ }^{18}$. However, another report revealed that the excess of palmitic acid in the human body could promote the dyslipidemia dan hyperglycemia ${ }^{19}$.

Table-1: Volatile Components Identified in Ethyl Acetate Fraction of Endophytic Fungus

\begin{tabular}{cccc}
\hline RT $(\mathrm{min})$ & IUPAC Name & $\mathrm{MW}\left(\mathrm{g} \mathrm{mol}^{-1}\right)$ & Peak area $(\%)$ \\
\hline 3.577 & 3-hydroxybutan-2-one & 88.11 & 13.59 \\
\hline 3.604 & 2-[2-(2-ethoxyethoxy)ethoxyethanol & 178.23 & 0.87 \\
\hline 3.825 & 2-ethylbutanoic acid & 116.16 & 1.16 \\
\hline 4.087 & 2-ethyl-2,4,5-trimethyl-1,3-dioxolane & 144.21 & 2.22 \\
\hline 5.197 & $2,3-$-butanedioldiacetate & 174.20 & 1.30 \\
\hline 26.264 & 4-isopropyl-1,6-dimethyl-1,2,3,4,4A,7-hexahydronaphtalene & 204.36 & 1.34 \\
\hline 28.289 & Hexadecanoic acid methyl ester & 284.48 & 1.53 \\
\hline 28.813 & Hexadecanoic acid ethyl ester & 284.48 & 8.53 \\
\hline 28.979 & 7-pentadecyne,-9-methylene & 221.41 & 11.64 \\
\hline 29.179 & Hexadecanoic acid & 270.46 & 1.08 \\
\hline 29.468 & Methyl linoleat & 308.51 & 1.96 \\
\hline 29.868 & 9-octadecanoic acid (Z)-ethyl ester & 310.52 & 26.40 \\
\hline 30.255 & 9,12-octadecanoic acid & 294.48 & 0.96 \\
\hline 30.344 & Hexadecanamide & 255.44 & 1.51 \\
\hline 30.517 & Trifluoroacetyl-isopulegol & 250.26 & 0.99 \\
\hline 30.910 & 9-chloro-1-azaphenoxathiin & 235.69 & 3.55 \\
\hline 31.413 & Octadeca-9,12-dien-1-ol & 280.50 & 0.80 \\
\hline 31.861 & 1-Methyl-2-pyrrolidinethione & 115.19 & 0.86 \\
\hline 33.130 & Cis-11-octadecanal & 268.47 & 3.46 \\
\hline 36.612 & 2-Methyl-2H-isoindole-1-carbonitrile & 156.19 & 7.17 \\
\hline 37.812 & (22E)-Ergosta-5,7,22-trien-3-ol & 396.65 & \\
\hline
\end{tabular}

(z,z)-9,12-Octadecadienoic Acid

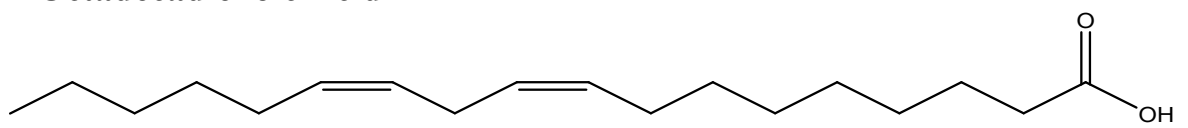

(z,z)-9,12-Octadecadienoic Acid

Linoleic acid (LA) is an essential nutrient that cannot be synthesised by the human body. Therefore, the nutrient must be taken from foods because humans cannot incorporate a double bond beyond the ninth carbon of a fatty $\operatorname{acid}^{20}$. LA; 18:2n-6 plays a significant role in cell physiology, immunity, and reproduction, and is an essential nutrient in diverse organisms ${ }^{21}$. LA is synthesized in plants, bacteria, and protozoa. As a necessary component of ceramides, linoleic acid involves the maintenance of the transdermal water barrier of the epidermis, LA also a precursor for other prominent PUFA members including arachidonic acid, eicosapentaenoic acid and docosahexaenoic acid which are essential nutrients for human brain development ${ }^{22}$. Biosynthesis of this compound in plant occurs either in two enzymatic processes (1) plasmodial enzyme (FAD6) where methyl station is utilized as a critical point and classified as $\omega-6$ desaturase enzyme by encouraging $\omega-6$ carbon. (2) extra-plastidial system and also known as oleate $\Delta 12$ desaturase (FAD2) which is very selective and specific to $\mathrm{C} 12$ and $\mathrm{C} 13^{9}$.

According to the recent reports, LA associates with the degradation of melanin production of human skin through dynamically accelerate the deterioration of tyrosinase, the enzyme responsible for the production of melanin. The clinical test revealed that topical application of $0.1 \%$ of LA could effectively treat melasma and brighten the darken skin due to UVB exposure ${ }^{23}$. Moreover, LA also plays a significant role in many biochemical pathways, thus possess useful medicinal properties such as cardio-protective and 
RASĀYAN J. Chem.

Vol. 12 | No. 4 |2284 - 2289| October - December | 2019

anti-inflammatory ${ }^{24,25}$. In addition to the biosynthesis of several necessary compounds in the human body, the essential oils are also commonly used as aromatic therapeutic agents ${ }^{26}$ and plasticisers ${ }^{27}$.

(22E)-Ergosta-5,7,22-triene-3-ol

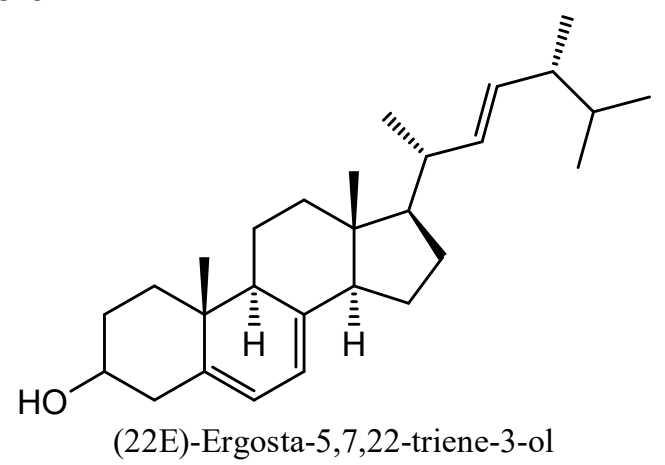

One of the interesting compounds found in the ethyl acetate extract of Aspergillus sp from mangrove root is the (22E)-Ergosta-5,7,22-trien-3-ol as above depicted structure. The compound is known as a precursor for the production of estradiol, the compound that has an antirachitic activity and known as provitamin $\mathrm{D}_{2}{ }^{28}$. A recent study showed that ergosterol extracted from edible mushrooms is proactive against leukaemia, and $25 \mu \mathrm{g}$ of the extract was able to inhibit the growth and induced apoptosis of HL60 cells completely ${ }^{29}$.

\section{CONCLUSION}

The presence of various bio-active compounds of the ethyl acetate extract of Aspergillus sp cultivated from the root of Rhizophora mucronata was confirmed using GC-MS analysis. There were up to 21 volatile compounds detected, and about six significant components were biologically active. However, phytochemical screening and isolation of individual compounds and proper biological activity tests will undoubtedly provide more meaningful results and will open a new area of investigation of different components and their potential pharmacological use.

\section{REFERENCES}

1. N. Bano, I.F. Rizvi, N. Sharma, M.H. Siddiqui and M. Kalim, Int. Res. J. Eng. Technol., 3(6), 1859(2016).

2. J. Guarro, J.M. Gene and A. Stchigel, Clinical Microbiology Reviews, 12(3), 454(1999), DOI: 10.1128/CMR.12.3.454

3. B.W. Nyongesa, S. Okoth and V. Ayugi, Advances in Microbiology, 5(4), 205(2015), DOI: 10.4236/aim.2015.54020

4. P. Raji, A.V. Samrot, D.B. Rohan, M.D. Kumar, R. Geetika, V.K. Sharma and D. Keerthana, Rasayan J. Chem., 12(1),123(2019), DOI:10.31788/RJC.2019.1214054

5. N.Y. Nma, A. Mann and B.M. Muhammad, J. Chem. Pharm. Res., 10(3), 75(2018).

6. T. Werpy, and G. Petersen, Top Value Added Chemicals from Biomass, (2004).

7. M. Wang, J. Fu, X. Zhang and T. Chen, Biotechnol. Lett., 34(10), 1877(2012), DOI:10.1007/s10529012-0981-9

8. S.J. Bae, S. Kim and J.S. Hahn, Sci. Rep., 6, 1(2016), DOI:10.1038/srep27667

9. T. Roncal, S. Caballero, M. Díaz de Guereñu, I. Rincón, S. Prieto-Fernández and J.R. Ochoa-Gómez, Process Biochem., 58, 35(2017), DOI:10.1016/j.procbio.2017.04.007

10. Q. Luo, J. $\mathrm{Wu}$ and M. Wu, Process Biochem., 49(8), 1223(2014), DOI: 10.1016/j.procbio.2014.05.005

11. J. Sun, L. Zhang, B. Rao, Y. Shen and D. Wei, Bioresour. Technol., 119, 94(2012), DOI: 10.1016/j.biortech.2012.05.108

12. K.G. Lee and T. Shibamoto, Food Chemistry, 74(4), 443(2001), DOI: 10.1016/S03088146(01)00161-3 
RASĀYAN $J$. Chem.

Vol. 12 | No. 4 |2284 - 2289| October - December | 2019

13. M. Balaban and G. Ucar, Orig. Orig., 60, 34(2002), DOI:10.1007/s00107-001-0251-3

14. T.K. Lim, 2014, Syzygium aromaticum, in Edible Medicinal and non-Medicinal Plants, Springer Science, New York, p.88, DOI:10.1007/978-94-017-8748-2

15. I.M. Sudarma, M.G. Darmayanti and Sarkono, Rasayan J. Chem., 12(2), 761(2019), DOI:10.31788/RJC.2019.1225115

16. M. Shirzad and S. Sardari, Organic \& Medicinal IJ, 7(3), 3(2018), DOI:10.19080/OMCIJ.2018.07.555716

17. H.P. Singh, S.S. Mishra, C.S. Sharma and N. Kumar, Int. J. Pharm. Technol. Biotechnol., 4(2), 10(2017).

18. Sjafaraenan and E. Johannes, J. Biol. Makassar., 1(1), 24(2016), DOI:10.20956/bioma.v1i1.1064

19. G. Carta, E. Murru, S. Banni and C. Manca, Front. Physiol., 8, (2017), DOI: $10.3389 /$ fphys.2017.00902

20. J. Whelan and K. Fritsche, Adv. Nutr. An. Int. Rev. J., 4, 311(2013), DOI:10.3945/an.113.003772.311

21. M. Malcicka, B. Visser and J. Ellers, Evol. Biol., 45(1), 15(2018), DOI:10.1007/s11692-017-9436-5

22. R. Block, S.A. Mousa and D. Swanson, Adv. Nutr. An. Int. Rev. J., 3, 1(2012), DOI: 10.3945/an.111.000893.Omega-3

23. H. Ando, 2017, Melanogenesis, in: Cosmetic Science and Technology: Theoretical Principles and Applications, Elsevier Inc. pp 729-736, DOI:10.1016/B978-0-12-802005-0.00044-6

24. J.S. García-pérez, S.P. Cuéllar-bermúdez, A. Arévalo-gallegos , J. Rodríguez-rodríguez, H.M.N. Iqbal, R. Parra-saldivar, Int. J. Mol. Sci., 17(9), 1528(2016), DOI:10.3390/ijms17091528

25. J. Orsavova, L. Misurcova, J.V. Ambrozova, R. Vicha and J. Mlcek, Int. J. Mol. Sci., 16, 12871(2015), DOI:10.3390/ijms160612871

26. B. Ali, N.A. Al-Wabel, S. Shams, A. Ahamad, S.A. Khan and F. Anwar, Asian Pac. J. Trop. Biomed., 5(8), 601(2015), DOI:10.1016/j.apjtb.2015.05.007

27. M. Hasan, Zulfadli, M. Nazar, R.F.I. Rahmayani, G. Fajri and H. Fansuri, Rasayan J. Chem., 12(3),1390(2019), DOI:10.31788/RJC.2019.1235326

28. A.C. Ross, B. Caballero, R.J. Cousins, K.L. Tucker and T.R. Ziegler, Modern Nutrition in Health and Disease, Lippincott William \& Wilkins, Philadelphia, p.279(2012).

29. T. Akei, M. Yoshida, M. Ohnishi-Kameyama and M. Kobori, Biosci. Biotechnol. Biochem., 69(1), 212(2005), DOI:10.1271/bbb.69.212

[RJC-5415/2019] 